\title{
1 A mitochondria-targeted antioxidant affects the carotenoid- based plumage of red crossbills
}

3

$10{ }^{1}$ Section of Ecology, University of Turku, Turku 20014, Finland.

$11{ }^{2}$ Departamento de Ecología Evolutiva. Museo Nacional de Ciencias Naturales - CSIC.

12 C/ José Gutiérrez Abascal 2, 28006 Madrid, Spain

$13{ }^{3}$ Instituto de Investigación en Recursos Cinegéticos, IREC (CSIC - UCLM - JCCM).

14 Ronda de Toledo 12, 13005 Ciudad Real, Spain.

$15{ }^{4}$ Department of Ornithology, Aranzadi Sciences Society, Zorroagagaina 11, E-20014

16 Donostia-San Sebastián, Spain.

17

18

19 *Corresponding author: carlos.alonso@csic.es

20 Telephone number: +3491411 1328 - 988978

21

22 Keywords: bird colouration, mito-targeted antioxidants, mitoQ, mitoTEMPO, sexual 23 signalling, shared-pathway hypothesis 


\section{Summary statement}

26 Antioxidants designed to penetrate the mitochondrial membrane increased avian

27 plumage redness but depending on pre-existing colouration. This supports

28 mitochondrial involvement in the evolution of carotenoid-based ornaments as reliable

29 quality signals.

30 


\section{ABSTRACT}

32 The mechanisms involved in the production of red carotenoid-based ornaments in 33 vertebrates are still poorly understood. Those colours generated by red carotenoids often 34 depend on the enzymatic production (ketolation) of these pigments from dietary yellow 35 carotenoids. Recently, it has been proposed that this conversion takes place at the inner 36 mitochondrial membrane (IMM). This implies that carotenoid ketolation and cell 37 respiration could share the same biochemical pathways. Such a link would favour the 38 evolution of red ketocarotenoid-based ornaments as reliable indices of individual 39 quality under a sexual selection scenario. We exposed captive male red crossbills (Loxia 40 curvirostra Linnaeus) to two different synthetic antioxidants designed to penetrate into 41 the IMM: a synthetic ubiquinone (mitoQ) and a superoxide dismutase mimetic 42 (mitoTEMPO). MitoQ decreased the blood levels of substrate yellow carotenoids and 43 tocopherol. This could be attributed to the characteristics of the mitoQ molecule, which 44 can distort the IMM structure, increasing free radical (superoxide) production and, 45 potentially, antioxidant consumption. Contrarily, mitoTEMPO-treated birds increased 46 the plasma levels of the second most abundant red ketocarotenoid of red crossbills (i.e. canthaxanthin). MitoTEMPO also increased plumage redness and total ketocarotenoid concentration in feathers among those birds exhibiting a redder plumage at the 49 beginning of the study, rising the plasma values of the main red pigment (350 hydroxyechinenone) in paler birds. The results as a whole support the involvement of 51 the mitochondrial antioxidant machinery in carotenoid biotransformation. The fact that 52 the initial plumage redness determined the effect of mitoTEMPO suggests that the 53 mitochondrial-based mechanism is intimately linked to individual quality. 


\section{Introduction}

How and why animal conspicuous colourations evolve are recurrent questions from Wallace's aposematism concept (Wallace, 1877) and Darwin's sexual selection (Darwin, 1871). Among showy colours exhibited by vertebrates, those produced by carotenoid pigments (many yellow-to-red ones) have attracted the most attention due to three particularities of these compounds (1) they cannot be synthesized by the animal organism from other substrates, thus being exclusively obtained with the diet, (2) they are theoretically scarce in food resources, which would make difficult its acquisition, and (3) they have physiological functions contributing to maintain homeostasis (e.g. Britton et al., 2004; von Schantz et al., 1999). This triangle has allowed formulating hypotheses explaining the evolution of coloured traits as reliable signals of individual quality in mate choice/intra-sexual competition contexts (see also Blount et al., 2009 for aposematism). These hypotheses establish trade-offs in the allocation of time/energy to searching for carotenoid-rich food vs. self-maintenance, and in the allocation of ingested carotenoids to colouration vs. homeostasis (see Endler, 1980; Grether et al., 1999; Kodric-Brown, 1985; Lozano, 1994; von Schantz et al., 1999). An inefficient trade-off solution would induce disproportionally higher costs for low-quality animals, making carotenoid-based coloured traits signals of individual quality (Grafen, 1990; Hasson, 1997; see also recently Penn and Számadó, 2019).

Some authors have, however, argued that dietary carotenoids could not be so scarce, at least among avian species (e.g. Hill and Johnson, 2012; McGraw, 2006). We must here note that first support for the scarcity assumption was provided from fish studies (Endler, 1980; Grether et al., 1999; Kodric-Brown and Brown, 1984). That argument would deactivate the trade-off-based hypotheses, removing those costs derived from the investment of resources in colouration (Hadfield and Owens, 2006; Koch and Hill, 2018; Koch et al., 2019; Svensson and Wong, 2011).

Particularly, Geoffrey Hill (2011) postulated that, instead of resource-allocation trade-offs, a physiological tight link between cell respiration efficiency and carotenoid metabolism exists, implying that some carotenoid-based coloured signals can directly transmit the intrinsic quality of the bearer (also Hill and Johnson, 2012). This means that these traits would act as quality indices instead of pure signals (see terminology in Biernaskie et al., 2014; also e.g. Maynard Smith and Harper, 2003). The idea was formulated in a broad context, giving a general hypothesis for the evolution of any sexual signal that was termed the "shared-pathway hypothesis" (Hill, 2011). 
Nonetheless, the shared-pathway hypothesis was developed from the particular case of ornaments generated by transforming common dietary yellow carotenoids (i.e. yellow xanthophylls) to red (keto)carotenoids by oxidoreductase enzymes supposedly located somewhere into the cell respiratory chain (Johnson and Hill, 2013). This theoretical framework was generated from some studies in house finches (Haemorhous mexicanus). In that species, males exhibit yellow to red plumages produced by xanthophylls (such as $\beta$-cryptoxanthin) or ketocarotenoids (mostly 3hydroxyechinenone; "3HOE”), respectively (Hill et al., 2002; Inouye et al., 2001; Johnson and Hill, 2013). The question was, however, firstly addressed by Otto Völker in 1957. Ornithologists at that time tried to understand why some birds (red crossbills Loxia curvirostra in particular) change their red plumage to a yellowish one under captivity conditions (also Weber, 1961). Although the lack of suitable carotenoid substrates in food under captivity could not be fully discarded (see Hudon 1994 and Hill 1994's discussions), the ornithologists suspected that other factors were implicated. Thus, Völker (1957) proposed that captive birds were unable to correctly perform the redox transformations converting yellow xanthophylls to red ketocarotenoids ( $\beta$ cryptoxanthin to 3-HOE, such as in house finches) due to flying restrictions under captivity. The idea was virtually overlooked during the following decades, probably as apparently unrelated to any evolutionary hypothesis.

Currently, studies supporting the shared-pathway hypothesis have begun to appear. A gene coding for an oxidoreductase (ketolase) enzyme candidate for yellow to red carotenoid transformations has recently been described in birds (Lopes et al., 2016;

111 Mundy et al., 2016). Moreover, high levels of yellow and, particularly, red carotenoids

112 have been found in the hepatocyte inner mitochondrial membrane (IMM) of house

113 finches (Ge et al., 2015; Hill et al., 2019). The liver seems to be the main carotenoid

114 transformation site in house finches, red crossbills and other Carduelinae species (del 115 Val et al., 2009b and cites therein; Hill and Johnson, 2012). The accumulation of red 116 carotenoids into the mitochondria supports the shared pathway hypothesis as this 117 organelle is responsible for cell respiration (Hill 2011), and particularly supports the 118 "inner mitochondrial membrane carotenoid oxidation hypothesis" (IMMCOH) as a 119 particular case of the main hypothesis (Johnson and Hill, 2013).

In the IMMCOH, red ketocarotenoids are considered molecularly similar to

121 ubiquinone, which is a key molecule in cell respiration transferring electrons across the 122 respiratory chain. Thus, transforming yellow to red pigments would share the machinery 
123 involved in ubiquinone biosynthesis and/or ubiquinone:ubiquinol redox cycle and, 124 hence, affect respiratory pathways (Johnson and Hill, 2013). An experimental finding in 125 another classical model, the zebra finch (Taeniopygia guttata; Vieillot 1817), has 126 provided additional support to the IMMCOH. Males bear a conspicuous red bill mostly 127 coloured by canthaxanthin and astaxanthin ketocarotenoids (McGraw and Toomey, 128 2010). Cantarero and Alonso-Alvarez (2017) administered a synthetic compound 129 targeted to mitochondria to captive males. This substance (mitoquinone mesylate or 130 mitoQ; Smith et al., 2003) introduces the redox-active aromatic ring of ubiquinone (i.e. 131 benzoquinone) into the IMM (e.g. Murphy and Smith, 2007, see Fig. 1). Zebra finches treated with mitoQ improved bill redness (Cantarero and Alonso-Alvarez, 2017).

133 Synthetic ubiquinone introduction into the IMM is attained by joining together 134 the antioxidant benzoquinone with a triphenylphosphonium cation $\left(\mathrm{TPP}^{+}\right)$that favours 135 molecule penetration into the IMM and its accumulation in the matrix side (Murphy and 136 Smith, 2007). This procedure has not only been applied to mitoQ production but to many other mito-targeted compounds (Murphy and Smith, 2007; Zielonka et al., 2017).

138 In mitoQ, the active benzoquinone is connected to $\mathrm{TPP}^{+}$by a linker group formed by a 139 10-carbon alkyl chain (i.e. decyl-TPP ${ }^{+}$or $\mathrm{dTPP}^{+}$). The length of this molecule, however, 140 seems to be responsible for increased membrane permeability, inhibition of the electron 141 transport chain (ETC) and higher superoxide radical generation (see Gottwald et al., 142 2018; Reily et al., 2013; Trnka et al., 2015). Interestingly, zebra finches only treated 143 with $\mathrm{dTPP}^{+}$developed paler bills than controls (Cantarero and Alonso-Alvarez, 2017).

144 This opens the question about how strong should have been the ubiquinone effect on colouration without the interfering role of the alkyl chain.

146 Here, we tested the impact of two mito-targeted antioxidants on the plumage and 147 tissue (blood and feathers) levels of carotenoids and antioxidant vitamins in male birds 148 from the same species used by Völker (1957) and Weber (1961) in their seminal 149 studies: the red crossbill. Although mitochondrial activity was not assessed, the level of 150 specific substrate and product (transformed) carotenoid pigments in blood and feathers 151 allowed us to infer the activity of biotransformation enzymes supposedly located at the 152 IMM. This replacement procedure avoided sacrificing wild birds as a biopsy would 153 have been needed to extract the liver mitochondria. Moreover, as an alternative to 154 mitoQ, mitoTEMPO (2-(2,2,6,6-Tetramethylpiperidin-1-oxyl-4-ylamino)-2155 oxoethyl)triphenylphosphonium chloride; Dikalova et al., 2010) was also tested. This 156 molecule includes a piperidine nitroxide that recycles ubiquinol (the reduced ubiquinone 
157 form) to ubiquinone (see Fig. 1; Trnka et al., 2008). This action reduces oxidative stress, 158 decreasing superoxide radical levels in mitochondria (Dikalova et al., 2010). In contrast 159 to mitoQ, the nitroxide is joined to $\mathrm{TPP}^{+}$by a shorter linker group than mitoQ, 160 theoretically inducing a lower distortion of the IMM structure (Fig. 1).

161 We predicted that mitoQ-treated birds, but particularly, mitoTEMPO-treated 162 ones, should develop a redder plumage and higher red ketocarotenoid concentrations in 163 both blood plasma and feathers than controls. Moreover, taking into account the 164 signalling theory (e.g. Biernaskie et al., 2014; Maynard Smith and Harper, 2003), we predict that the intrinsic individual quality should affect the efficiency of the treatments. To address this, the sample was divided by plumage redness before the experiment, categorizing high- or low-redness crossbills that should theoretically represent high- or low-quality individuals (e.g. Galván et al., 2015 for a similar approach). If the availability of substrate carotenoids is unconstrained in food, the addition of mitochondrial antioxidants should improve colouration. We may a priori predict that mito-targeted antioxidants should only or mostly benefit low-quality individuals as they could, in some way, be constrained in colour expression. Low-quality individuals could not only be constrained in mitochondrial mechanisms linked to carotenoid biotransformation but in other processes such as the capacity to absorb substrate carotenoids or transport them in the blood (e.g. Madonia et al., 2017). In that case, circulating levels of $\beta$-cryptoxanthin or other potential substrates (e.g. $\beta$-carotene; see McGraw, 2006, p. 215) should be lower in low-redness birds compared to high-redness ones. We must note that yellow carotenoid uptake is not only a passive diffusion mechanism but also depends on specific receptors in enterocytes (Hill and Johnson, 2012; Jlali et al., 2014; Toomey et al., 2017).

\section{MATERIAL AND METHODS}

\section{Experimental design}

184 Male red crossbills were captured by means of mist nets during March 2017 at three 185 different locations (i.e. Isaba, Leire and Lakuaga) at the Pyrenean region (Northern 186 Navarra; Spain). The age was determined at the field by the moult pattern (Jenni and 187 Winkler, 1994). Juveniles were excluded from the study. Forty-seven males were finally 188 used. The sample included eighteen 1st year autumn/2nd year spring (8-12-month-old) 189 males $(38 \%)$. The forty-seven birds were transferred to facilities also located at the 190 Pyrenean region on the same day of capture (i.e. Instituto de Formación Agroambiental, 
191 IFA; Jaca, Huesca, Spain). All the birds were housed in four contiguous aviaries. These

192 were $5.9 \times 2.5 \times 2.2$ m (length, width, height, respectively; i.e. $14.75 \mathrm{~m}^{2}$ surface, 32.45

$193 \mathrm{~m}^{3}$ volume each one). Every aviary was partially covered with a roof $\left(4 \mathrm{~m}^{2}\right)$ to provide

194 protection during rainy days. Food was composed of Pinus sylvestris pine nuts

195 (Vilmorin, France) and cones, as well as sunflower and hemp seeds. Food, water and

196 grit were all provided ad libitum. Pine branches with leaves were added for behavioural

197 enrichment. The experiment started after one month approximately to allow acclimation

198 (mean 33 days, range 30-56 days). The first manipulation (carotenoid supply) started on

199 May $15^{\text {th }}$, 2017. Birds were captured when required by using a shade net that

200 transformed each aviary in a funnel. This minimized capture stress because less than

201 five minutes were needed to capture all the birds.

202

\section{Dietary carotenoid supplementation}

204 Red crossbills are specialized conifer seed feeders, but it is unclear what food item (e.g. 205 pine leaves, resin) is the dietary source of the main substrate carotenoid (i.e. $\beta$ cryptoxanthin) involved in producing the red pigment 3HOE (del Val et al., 2009a; 2009b). In fact, pine cones contain relatively low $\beta$-cryptoxanthin amounts $(<0.1$ $\mathrm{mg} / \mathrm{Kg}$ in del Val et al., 2009b), and we did not find other food items that pine nuts into the crossbill gizzard during annual ringing campaigns (Daniel Alonso, personal communication). To discard a loss of redness due to $\beta$-cryptoxanthin scarcity, the birds received a dietary supplement. It was made by mixing two products: (1) a dry extract of mandarin (Citrus unshiu) that contained $\beta$-cryptoxanthin at $0.17 \mathrm{mg} / \mathrm{g}$ (ref. 0677,

213 Supersmart; Luxembourg) and (2) a synthetic $\beta$-carotene provided in corn oil that

214 contained $291 \mathrm{mg} / \mathrm{g}$ of $\beta$-carotene and $7 \mathrm{mg} / \mathrm{g}$ of tocopherol ( $\beta$-carotene $30 \% \mathrm{FS}$, DSM

215 Nutritional Products, Switzerland). These figures were verified by HPLC analyses such

216 as reported below. The $\beta$-carotene supplement was chosen because this compound is 217 more abundant in crossbill natural food than $\beta$-cryptoxanthin (del Val et al., 2009b).

218 Moreover, $\beta$-carotene can be transformed into retinol but also enzymatically modified to

219 echinenone by one oxidation and then to canthaxanthin by another oxidation step or, 220 instead, to $\beta$-cryptoxanthin by one oxidation and one hydroxylation (McGraw, $2006 \mathrm{p}$. 221 215).

The synthetic $\beta$-carotene solution was diluted in peanut oil (SIGMA-ALDRICH ref. P2144) at 1:100 volumes to reduce its very high concentration. We here used peanut

224 oil because it has previously been used in avian studies manipulating dietary 
carotenoids (e.g. Saino et al., 2000) and because it allows dilution without adding substantial carotenoid amounts $(0.1 \mathrm{mg} / \mathrm{kg}$ in crude oil; Carrín and Carelli, 2010). The mandarin dry extract was then added to that solution $(19.3 \mathrm{~g}$ per $100 \mathrm{~mL}$; i.e. the highest concentration that we were able to dilute), the result being mixed by a vortex and also sonication (30 s) in cold water. The mixture was maintained refrigerated and away from light, and regularly made to avoid oxidation (Alonso-Alvarez et al., 2004). All the birds received the carotenoid mix by pipetting 150 microliters into the mouth every other day from the cited date until June 18 (36-day period).

A group of five red male crossbills (see colour categories below) was used to verify that the carotenoid supplement indeed increased circulating levels of substrate carotenoids. Accordingly, they received the same oil amount (150 microliters every other day throughout the experiment) but containing peanut oil only and no additional pigment. They were also injected with saline only (see injection treatment below) to allow comparisons with the remaining birds. At least one bird of this small group was present in each aviary. The five birds were, nonetheless, excluded from the analyses testing antioxidant treatment effects.

\section{The antioxidant treatment}

243 The males receiving the carotenoid supplement were randomly assigned to one of the 244 three antioxidant treatments (control, mitoQ or mitoTEMPO, $n=14$ per group; $N=42$ ).

245 The number of birds older than one year was fully balanced among these groups $\left(\chi^{2}=\right.$ $2460.00, \mathrm{df}=2, P=1.00)$. All these birds were subcutaneously injected into the back every 247 other day throughout 20 consecutive days. When measured the day before the first 248 injection, no significant difference among treatments, colour categories or its interaction 249 was detected on the tarsus length, body mass or size-corrected body mass (i.e. by adding 250 tarsus length as a covariate to a normally distributed GENMOD testing body mass; all $251 P$-values $>0.23$; see also Statistical analyses section). Each injection had $130 \mu \mathrm{L}$ 252 volume of saline plus MitoQ or, alternatively, MitoTEMPO. MitoQ was kindly 253 provided by Prof. Michael P. Murphy, whereas mitoTEMPO was purchased from 254 SIGMA-ALDRICH (ref. SML0737). MitoQ was administered at $1 \mathrm{mM}$ (2.27 $255 \mathrm{mg} / \mathrm{Kg} / \mathrm{day}$ ), which is the dose that induced an increase in bill redness in male zebra 256 finches (Cantarero and Alonso-Alvarez, 2017). With regard to mitoTEMPO dosage, we 257 first considered a study where mice reduced mitochondrial superoxide production and 258 oxidative damage in muscles and vascular tissue when they received $1.5 \mathrm{mg} / \mathrm{Kg} /$ day in 
259 saline subcutaneously injected throughout 12 weeks (Vendrov et al. 2015; see also

260 Nazarewicz et al., 2013 for same dosage and effect as anticancer molecule). We then 261 performed a pilot study involving 10 male zebra finches randomly assigned to five 262 different concentrations $(0,0.334,0.668,1.335$ and $2.67 \mathrm{mg} / \mathrm{Kg} /$ day $)$ subcutaneously 263 injected in saline every two days for three weeks. The highest dose $(2.67 \mathrm{mg} / \mathrm{Kg} / \mathrm{day}$; $2643 \mathrm{mM}$ ) was finally chosen as we did not find a significant correlation between dose and 265 body mass change (\%) suggesting any health impairment (Spearman's $r=0.320, P=$ 266 0.367), and no evident toxicity symptoms (behaviour changes, fatigue, lack of 267 alertness). Additionally, the change (\%) in redness at the upper bill mandible increased 268 with dosage (Spearmans' $r=0.82, P=0.01$; see also Cantarero \& Alonso-Alvarez 2017 for colour analysis methods).

270 All the crossbills were weighed and photographed on May 23. The following 271 day a blood sample (150 microliters) was taken from the jugular vein and birds were 272 injected by the first time, that is, ten days after the start of the carotenoid 273 supplementation, which should have allowed birds to circulate enough substrate 274 carotenoids for transformation. Data obtained in these two days (May 23 and 24) 275 provided the initial values of the experiment. Two days after the first blood sampling all 276 the feathers in the rump region were plucked to induce a synchronized feather growth.

277 The injection period ended on June $14^{\text {th }}$, i.e. when every bird had received 11 injections 278 (a three- week exposure, approximately). A second (final) blood sample was taken on 279 June 12th to determine the final levels of plasma carotenoids under antioxidant 280 exposure. Birds were allowed to end the feather regrowth until June 23th, when they were again weighed and photographed, and the new rump feathers were carefully removed for quantifying carotenoids. Feather samples were stored at $-80^{\circ} \mathrm{C}$. Birds were released in the original location when they were again fully feathered (July $10^{\text {th }}$ ). Four birds were found died before the end of the experiment without clear signs of illness or body mass loss (one control, two mitoQ- and one mitoTEMPO-birds). Mortality did not differ among treatments $\left(\chi^{2}=0.55, \mathrm{df}=3, P=0.76\right)$. Additionally, the second blood sample of one mitoTEMPO and one mitoQ-bird, as well as the rump feather sample of one mitoQ-individual, could not be analysed due to problems during the laboratory processing. Finally, one control bird was unable to produce enough rump feathers for analyses. Therefore, the final sample sizes were 37, 36 and 35 for colour, feather and plasma analyses, respectively. No colour category $\mathrm{x}$ antioxidant treatment combination 
292 included less than five birds, and the sample was always balanced (all $\chi^{2}$ tests: $P>$ 293 0.20).

\section{Colour measurements}

296 The red crossbill plumage was photographed (Canon EOS 50) by putting the birds 297 always at the same position and fixed distance from the objective (Canon Macro Lens 298 EF 50 mm). A Kaiser Repro Base (Kaiser Fototechnik, Buchen) including a gridded board and a column to place the camera at the same height was used (distance from the

300 board to the lens: $38 \mathrm{~cm}$ ). The base was covered with opaque grey cellular 301 polycarbonate sheets placed in a vertical position to cover the four sides of the board but 302 allowing to enter the camera objective and ring flash (Canon Macro Ring Lite MR303 14EX) from the top. The sheets were perforated to allow entering the hands of a person 304 that would hold the body of the bird resting on the board surface. All the open surfaces were covered with PVC blackout fabric to reduce the light on the board surface. The bird was placed in a prone position by pulling the bill and legs. A standard grey card

307 (Kodak, NY, USA) was used as a reference, being placed next to the bird's flank on the 308 board surface and always in the same position. The focus and diaphragm of the camera, 309 as well as the ring flash, were all manually fixed to avoid the interference of automatic 310 functions. Digital photographs were standardized and analysed using the recently 311 developed 'SpotEgg' software, an image-processing tool for automatized analysis of 312 avian colouration that solves the need for linearizing the camera's response to subtle 313 changes in light intensity (Gómez and Liñán-Cembrano, 2017). We have previously 314 shown that picture-based measurements are highly correlated with the redness 315 measurement (i.e., red hue) obtained from portable spectrophotometers (Alonso-Alvarez 316 and Galván, 2011; Mougeot et al., 2007). SpotEgg, however, allows the user to 317 manually draw any region and provide information about its colouration, shape or other 318 features (ESM in Cantarero and Alonso-Alvarez, 2017 for additional details). The 319 measure of a large delimited area, as opposed to portable spectrophotometers that 320 analyse the colour of reduced spots (usually 1-2 mm), makes this tool useful for 321 evolutionary biologists aiming to capture most of the variability among individuals 322 (Gómez and Liñán-Cembrano, 2017). Accordingly, for each animal, the average of red, 323 green, and blue components of the rump surface was calculated. We then determined 324 hue values by means of the Foley \& van Dam (1982) algorithm. Repeatability (Lessells 
and Boag, 1987) calculated on a set of digital photographs measured twice $(n=30)$ was very high $(R=0.99, P<0.001)$.

\section{Initial colour variability in our sample of birds}

329 Large variability in plumage colour was present in our sample, birds showing body

330 feathers ranging from yellow to red and including intermediate phenotypes such as 331 homogeneous orange or individuals with small patches of red to yellow feathers 332 randomly distributed in the body (patchy birds). These male phenotypes are frequent in 333 this species (del Val et al., 2014). To take into account this in our statistical analyses, 334 the redness value of the rump at the start of the experiment was used to divide the sample by its median. This should theoretically classify birds in high- and low- quality signallers (Galván et al., 2015 for a similar procedure). This led to two blocks (23 highredness and 24 low-redness birds) well-balanced among treatments $\left(\chi^{2}=0.76, \mathrm{df}=2, P\right.$ $=0.683 ;$ see also ESM).

The age category (8-12-month-old vs older birds; see above) was balanced between the two colour categories in both controls (Fisher's two-tailed test $P=0.301$ ) and mitoTEMPO-birds $(P=0.580)$. However, a trend to significance was found among mitoQ-birds $(P=0.091 ; n=14)$. Here, low-redness birds only included an individual older than one year (1/8), whereas this age group showed a higher frequency (4/6) in high-redness birds. Therefore, colour-related effects in mitoQ birds could partly have been due to age differences. However, the colour category did not show any significant effect among mitoQ birds (see Results). Moreover, when the two-level age factor was added to the statistical models, final models and conclusions were unaffected (data repository at DIGITAL.CSIC, doi: pending on acceptance).

\section{Sample processing}

351 Blood was immediately stored in a cold box $\left(1-6^{\circ} \mathrm{C}\right)$ and centrifuged within $6 \mathrm{~h}$ at $10,000 \mathrm{rcf}$ for $5 \mathrm{~min}$ at $4{ }^{\circ} \mathrm{C}$. Plasma samples were then separated and stored at $-80^{\circ} \mathrm{C}$ until the analyses. Carotenoid analysis in plasma was performed as described before in

354 García-de Blas et al. $(2011 ; 2013)$. Feathers in the regrown rump were carefully plucked and stored at $-80{ }^{\circ} \mathrm{C}$. These feathers, when analysed, were defrosted and the yellow-tored part of each feather was cut by a scissor. The total mass of this feather sample was weighed for each bird (mean $8.4 \mathrm{mg}$, range 4.4-13.6 mg), and this measure used for concentration calculations. The carotenoids in feather samples were extracted following 
359 the method described by McGraw et al. (2003). In order to avoid any external

360 contamination of carotenoids from uropygial secretion, the feathers were washed with 361 ethanol, hexane and then air dried. Then, the feathers were extracted in a mixer mill with grinding steel balls (MM400, Retsch, Haan, Germany) for 3 min with $5 \mathrm{~mL}$ of methanol and $50 \mu \mathrm{l}$ of internal standard (retinyl acetate at $0.5 \mathrm{mM}$ ). Then, the extract was filtered through a nylon syringe filter $0.2 \mu \mathrm{m}$, dried under $\mathrm{N}_{2}$ stream and finally resuspended with $200 \mu \mathrm{l}$ of ethanol and transferred to a chromatographic vial for HPLC analysis.

\section{Carotenoid and vitamin quantification}

369 The analyses of carotenoids and vitamins $\mathrm{A}$ and $\mathrm{E}$ in the rump feathers and plasma were 370 performed by HPLC (Agilent Technologies 1200 series) with DAD and FLD detectors, 371 following the methods described by Rodríguez-Estival et al. (2010), García-de Blas et 372 al. $(2011 ; 2013)$ and Alonso-Alvarez et al. (2018) with some modifications. Compound 373 separation required a column Zorbax Eclipse XBD-C18 (4.6x150 mm, $5 \mu \mathrm{m})$ with a 374 precolumn Zorbax Eclipse XBD-C18 $(4.6 \times 10 \mathrm{~mm}, 5 \mu \mathrm{m})$. The injection volume was 20 $375 \mu \mathrm{L}$. The chromatographic conditions consisted of gradient elution of two phases (A: 376 formic acid $0.1 \%$ in water; B: formic acid $0.1 \%$ in methanol). The initial conditions 377 were $50 \% \mathrm{~A}$ and $50 \% \mathrm{~B}$, changing to $0 \% \mathrm{~A}$ and $100 \% \mathrm{~B}$ in 20 minutes, keep this 378 condition 30 minutes and return to initial conditions in 5 minutes, all time the flow rate 379 was $1 \mathrm{~mL} / \mathrm{min}$. Standards of lutein, zeaxanthin, canthaxanthin, astaxanthin, 3HOE and $380 \beta$-cryptoxanthin and $\beta$-carotene were purchased from CaroteNature (Lupsingen, 381 Switzerland). Retinyl acetate (used as an internal standard) and standards of retinol and $\alpha$-tocopherol were provided by Sigma-Aldrich. Concentrations were determined from

383 the calibration curve of their standards and linear calibration adjustments. No esterified carotenoids were detected. Carotenoid and vitamin concentrations in plasma or feathers were expressed as $\mathrm{nmol} / \mathrm{mL}$ and $\mathrm{nmol} / \mathrm{g}$ for plasma and feathers, respectively.

\section{Statistical analyses}

388 First, the difference in circulating carotenoid levels between birds fed or not with the carotenoid supplement was tested by non-parametric Fisher exact tests, Pearsons' $\chi^{2}$ or

390 Mann-Whitney U tests. This avoided the problem of unbalanced sample sizes (only five 391 birds used as controls here), lack of normality or heteroscedasticity. We must note that 
392 the concentration of red ketocarotenoids in plasma showed a high frequency of zero393 values, ranging from $36.5 \%$ in plasma $3-\mathrm{HOE}$ to $70.7 \%$ in plasma astaxanthin.

Subsequently, generalized linear models were used to test the antioxidant treatment effect and its interaction with the two colour categories $(N=35-37$, see above). This allowed specifying the distribution type. The GENMOD procedure in SAS 9.4 was used. In these models, sample sizes and variances were well balanced among groups. However, the lack of normality remained due to zero inflation in most ketocarotenoids as well as $\beta$-cryptoxanthin and an unknown derivative of $\beta$ cryptoxanthin ("UD- $\beta$-cryptoxanthin"; see below) both in feathers only. In all these variables, the adjustment to zero-inflated Poisson or, instead, negative binomial distributions were tested (e.g. Ridout et al., 1998). Only the zero-inflated negative binomial (ZINB in SAS) distribution met the no over-dispersion criterion tested by Scaled Pearson's $\chi^{2}$. Yellow xanthophylls and vitamins $(\alpha$ - and $\gamma$-tocopherol fractions were summed to obtain total tocopherol) in plasma, as well as rump redness, were all normally distributed (a normal distribution specified in GENMOD). Nonetheless, the sum of the five unknown plasma xanthophylls (UX-xanthophylls; see below), as well as the sum of all red ketocarotenoids in feathers, required a log-transformation. Feather astaxanthin was only found in two birds, its variability being not analysed, whereas feather canthaxanthin required a square root-transformation. Finally, the body mass change (\%) from the start of the antioxidant treatment to the second blood sampling or, instead, to the date of colour measurement, were normally distributed and also tested by GENMOD for coherence.

The use of the GENMOD procedure prevented to include the aviary as a random

415 factor. However, the three treatment groups $\left(\chi^{2}{ }_{6}=2.56, P=0.861\right)$, the two colour categories $\left(\chi^{2}{ }_{3}=0.46, P=0.927\right)$, or the six groups resulting from its interaction $\left(\chi^{2}{ }_{15}=\right.$ $0.46, P=0.902$ ) were well-balanced among the aviaries.

418 With regard to covariates, the carotenoid level at the first blood sampling was 419 tested in GENMOD models analysing carotenoid concentration variability. In the case 420 of the rump colour, the initial redness (before plucking) was not added as a covariate 421 because the colour category captured its variability. Instead, saturation (purity) and 422 brightness (lightness) were included as covariates to assess colour variability fully 423 independent of these parameters (Fitze and Richner, 2002). In any event, the results did 424 not vary when these two terms were removed (treatment x colour category: $P=0.025$ ). 
425 Initial body mass was also excluded as a covariate in models testing body mass change.

426 Similar results were, anyway, obtained when testing final body mass controlled for an 427 initial weight covariate, but we considered that body mass change provides more useful 428 information. Body mass change models included tarsus length as a covariate to correct 429 for body size variability.

430 Backward stepwise procedures were used to remove terms at $P>0.10$. Only two exceptions were made in the models shown in tables: (1) the brightness covariate that was maintained in the redness model to assess hue independently of lightness (see above) and (2) the interaction treatment $\mathrm{x}$ colour in the model testing total red carotenoids in feathers as it allowed to check variability among the six group combinations and then visually compare them to that found in the rump redness model (Fig. 5A and B). Satterthwaite-corrected DFs and least-square means \pm SEs are reported. LSD tests were used for pair-wise comparisons.

\section{RESULTS}

\section{Description of carotenoids and vitamins in blood and feathers}

441 In plasma, $\beta$-cryptoxanthin, lutein, astaxanthin (but only at the second sampling), canthaxanthin, 3HOE and echinenone were detected. Five unidentified carotenoids were also found. Maximum wavelengths and retention times of these unidentified compounds (see Table S1 in ESM) suggested that they were closer to yellow xanthophylls such as lutein or $\beta$-cryptoxanthin. Retinol and $\alpha$ - and $\gamma$-tocopherol were also detected. Finally, in the rump feathers, $\beta$ cryptoxanthin, an unidentified derivative (probably an isomer) of $\beta$-cryptoxanthin (“UD- $\beta$-cryptoxanthin"; see ESM), lutein, astaxanthin, canthaxanthin, $3 \mathrm{HOE}$ and echinenone were detected. Neither retinol or tocopherol was found in feathers (see also Table S2 in ESM for concentration descriptions).

\section{Supplementary carotenoid effects}

452 In terms of plasma values, $\beta$-cryptoxanthin differed between both groups at both the 453 first and second sampling events $(U=0.01, P=0.001$ and $U=8.00 P=0.001$, 454 respectively; other pigments $P>0.12$ ). Carotenoid-supplied birds showed $\beta$ cryptoxanthin values several times higher than controls at both the first (x12 times: median, range: $0.34,0.097-0.784$ vs. $0.028,0-0.075 \mathrm{nmol} / \mathrm{mL}$, respectively) and second 
tocopherol $(U=33.0, P=0.018)$ differed at the second blood sampling, with those birds

460 receiving the supplement showing higher and lower levels than controls, respectively 461 (retinol: 5.74, range 3.13-9.98 vs. 4.43, range 3.98-6.12 nmol/mL; tocopherol: 180.48 , range 0-383.6 vs. 241.97, range $179.2-330.5 \mu \mathrm{M})$.

In terms of feather composition, no control bird for the dietary supplement

464

465

466

467

468

469

470

471

472

473

474

475

476

477

478

479

480

481

482

483

484

485

486

487

488

489

490 (those only receiving peanut oil) deposited $\beta$-cryptoxanthin or echinenone in the rump (both absence/occurrence Pearsons' $\chi^{2}$-tests showed $P<0.01$ ). The other pigments were found in both groups. When variability in concentrations was assessed, the effect on $\beta$ cryptoxanthin and echinenone was also significant (Mann-Whitney $U=10, P=0.001$ and $U=30, P=0.013$, respectively). Among other feather pigments, only canthaxanthin showed a trend to significance $(U=44, P=0.069)$, with supplement birds showing higher values (mean, range: 4.82, 0-17 vs. 2.12, 0-6 nmol/g, respectively). Finally, the redness of the moulted rump differed as expected ( $U=21, P$ $=0.005$; supplemented birds: $2.36,0.75-5.56$; controls: 0.87, 0-1.78).

No bird in this study attained an intense red rump, even when supplied with high levels of carotenoids in food (see ESM). The colour of the moulted rump declined $35.9 \%$ in the whole of the sample, ranging from yellow to pale orange. In fact, the percentage of red pigments in feathers only reached $22 \%$ approximately of the total amount of carotenoids (Table S2 in ESM).

\section{Mito-targeted antioxidant effects on body mass}

The birds involved in the antioxidant experiment gained body mass from captivity to the first antioxidant injection (mean \pm SE: $3.32 \pm 0.82 \%$ ). From that date, the treatment affected body mass change to the second (last) blood sampling $\left(\chi^{2}=70.7, \mathrm{df}=2, P=\right.$ 0.020; tarsus length covariate: $\chi^{2}=2.62$, $\left.\mathrm{df}=1, P=0.106\right)$. MitoQ-birds gained less mass than controls or mitoTEMPO-birds (both $P<0.017$; mitoQ: $0.018 \% \pm 0.945$, control: $3.198 \% \pm 0.944$; mitoTEMPO; $3.237 \% \pm 0.943$; control vs. mitoTEMPO: $P=$ 0.977). When the body mass change was tested to the date of colour measurement, the treatment again became significant $\left(\chi^{2}=6.84, \mathrm{df}=2, P=0.033\right.$; tarsus length: $\chi^{2}=6.12$, $\mathrm{df}=1, P=0.013)$. However, birds in both treatments gained less mass than controls, although pairwise comparisons did not reach significance (both $P<0.070$; mitoQ: 2.590 $\% \pm 0.903$, control: $5.471 \% \pm 0.871$; mitoTEMPO; $2.734 \% \pm 0.871$; mitoQ vs. 
491

492

493

494

495

496

497

498

499

500

501

502

503

504

505

506

507

508

509

510

511

512

513

514

515

516

517

\section{8}

519

520

521

522

523

mitoTEMPO: $P=0.909$ ). The colour category or its interaction with treatment were never significant (all $P$-values $>0.10$ ), being removed from these models.

\section{Mito-targeted antioxidant effects on blood composition}

In the case of yellow xanthophylls potential used as the substrate for ketocarotenoid production (Table 1), $\beta$-cryptoxanthin levels were the lowest in mitoQ treated birds (Fig. 2A), whereas mitoTEMPO and control birds did not differ $(P>0.123)$. Similar results were found for lutein, UX and total tocopherol (Figs. 2B-D). The colour group did not influence these models (all $P>0.40$ ).

In terms of red ketocarotenoids, mitoTEMPO-crossbills showed higher plasma canthaxanthin values than other groups (Table 1 and Fig. 2E). Only the initial value covariate remained significant in the zero-inflated part of this model as higher initial values led to lower probabilities of zero level at the second sampling (Table 1). The interaction with the colour category was removed at $P>0.22$.

In contrast, the model testing $3 \mathrm{HOE}$ detected a significant interaction (Table 1; Fig. 3). Low-redness mitoTEMPO birds showed significantly higher values than highredness birds in the same treatment, whereas the same comparison in controls tended to significance in the opposite direction $(P=0.093$; Fig. 3). Low-redness mitoTEMPO birds also showed significantly higher $3 \mathrm{HOE}$ values than low-redness birds from the other two groups and high-redness mitoQ-birds. The latter group showed the lowest mean $3 \mathrm{HOE}$ values, and circulated significantly less $3 \mathrm{HOE}$ than high-redness controls or high-redness mitoTEMPO- birds (but the latter $P=0.057$; other comparisons: $P$ values > 0.12). Furthermore, the probability of attaining a zero value was higher in mitoQ-birds compared to controls $(P=0.029$ in Table 1$)$. To conclude, the other two red pigments in plasma (i.e. astaxanthin and echinenone), as well as retinol, did not show any significant effect (all P-values $>0.10$ ).

\section{Mito-targeted antioxidant effects on feather pigments}

In rump feathers, the xanthophyll models, i.e. $\beta$-cryptoxanthin and UD- $\beta$-cryptoxanthin, and the model testing echinenone only retained the treatment factor (Table 2), with mitoQ-birds showing lower levels than the other groups (mitoTEMPO vs control always $P>0.10$; Figs. 4A-C). The zero-inflated part of these models did not retain any term (all $P$ 's $>0.15)$. 
Lutein and Sqrt-transformed canthaxanthin models did not show any significant

525

526

527

528

530

531

532

533

534

535

536

537

538

539

540

541

542

543

544

545

546

547

548

549

550

551

552

553

554

555

556

557 effect (all $P$ 's $>0.12$ ) and are not reported. Furthermore, 3HOE levels were apparently unaffected by the treatment or its interaction with colour category (all $P$-values $>0.40$ ). Only a weak trend to significantly higher levels in high- vs low-redness birds was found $\left(\chi^{2}=2.58, P=0.108 ; 36.16 \pm 8.29\right.$ and $22.22 \pm 4.41 \mathrm{nmol} / \mathrm{g}$, respectively $)$.

However, if the total level of red pigments in feathers is tested instead, the interaction did not reach significance (Table 2), but mitoTEMPO-birds showed significantly higher values than controls among high-redness individuals $(P=0.038$; Fig. 5A). The first group also showed a trend to significantly higher values than highredness mitoQ-birds $\left(P=0.087\right.$; other $P^{\prime}$ values $\left.>0.12\right)$. An alternative model testing the sum of yellow carotenoids neither detected a significant interaction $(P=0.824)$, and no term remained in the model (all $P>0.20$; pairwise comparisons: $P$ 's $>0.10$ ).

\section{Mito-targeted antioxidant effects on rump redness}

The interaction between colour and treatment was here significant (Table 2 and Fig. 5B). Agreeing with feather red pigments (Fig. 5A), the rump of high-redness mitoTEMPO-birds was significantly redder than the rump of high-redness controls (Fig. 5B). High-redness mitoTEMPO-birds also showed significantly redder rumps than lowredness mitoTEMPO-birds and mitoQ-birds and a trend to significantly redder rumps than low-redness controls (i.e. $P=0.087$; other $P$ 's $>0.12$ ).

\section{DISCUSSION}

Taking into account the specific characteristics of mito-targeted antioxidants (Dikalova et al., 2010; Murphy and Smith, 2007; Zielonka et al., 2017), our results as a whole seems to support the IMMCOH assumption describing that the mitochondrial membrane is the cell site where yellow carotenoids are biotransformed. Particularly, mitoTEMPO affected rump redness, total ketocarotenoid levels in feathers and canthaxanthin and $3 \mathrm{HOE}$ values in plasma. Most of these effects were, moreover, influenced by individual quality assigned by plumage redness before the experiment. However, contrarily to predictions, the treatment improved colouration only among the redder (supposedly high-quality) birds, but not among paler individuals.

Independently of colour categories, we must first note that most of our birds gained body mass probably due to reduced activity and ad libitum food. However, birds treated with mito-targeted antioxidants did not gain so much weight as controls. This 
558 was first detected in mitoQ-treated crossbills. The same mitoQ-induced effect was 559 found in male zebra finches, although under other housing conditions (i.e. birds paired 560 in cages; Cantarero and Alonso-Alvarez, 2017). Nevertheless, zebra finches only treated with the $\mathrm{dTPP}^{+}$did not report that effect, suggesting that reduced mass gain is due to 562 changes in redox activity (unpublished results). We can speculate that ubiquinone could 563 increase cell respiration rates, leading to consuming energy stores. In fact, ubiquinone is 564 known to reduce fatness in mammalian models (Allen and Vickers, 2014 and references therein) and mitoQ and mitoTEMPO injections have also shown to reduce body mass in obese rodents (Fink et al., 2017; Gutiérrez-Tenorio et al., 2017; Jeong et al., 2016).

MitoQ-birds also showed lower plasma levels of yellow xanthophylls and tocopherol (Fig. 2). The effect could, at first glance, be attributed to lower food intake. Nonetheless, when body mass change was added as a covariate it always reported $P$ values $>0.25$. Tocopherol variability was, however, significantly associated with body mass change, but inversely, decreasing with mass gain (body mass gain covariate: $\chi^{2}=$ $12.48, P=0.0004$; slope $\pm \mathrm{SE}:-6.37 \pm 1.80$; the antioxidant treatment effect remained significant at $P<0.001)$. We may, alternatively, propose that mitoQ reduced carotenoid and tocopherol intestinal absorption. However, literature in mammals, contrarily, suggests that mito-targeted antioxidants protect the functionality of intestinal cells (e.g. Hu et al., 2018; Wang et al., 2014). As a third option, mitoQ may have increased oxidative stress due to its long alkyl linker group (Fig. 1; Gottwald et al., 2018; Maroz et al., 2009; Reily et al., 2013; Trnka et al., 2015; Yasui et al., 2017). This may have promoted the consumption of tocopherol and xanthophylls to be used as radical scavengers (Britton et al., 2004; Panda and Cherian, 2014). Unfortunately, no measure of oxidative damage was tested, and hence, no firm conclusion can be made here.

The apparently negative (or non-significant) effects exerted by mitoQ on our crossbills contrast with the positive effect of this antioxidant on the bill redness of male zebra finches (i.e. Cantarero and Alonso-Alvarez 2017). This highlights the complexity and diversity of carotenoid-based signalling mechanisms (McGraw 2006). Zebra finches and red crossbills differ in the type of carotenoid-based ornament (bill vs. plumage, respectively) and in the carotenoid biotransformation tissues (bill vs. liver; del Val et al. 2009a,b; Mundy et al. 2016). If we consider that the liver is a vital organ devoted to detoxification and other critical functions, we may hypothesize that a shared

590 (or competitive) pathway involved in sexual signalling (Hill 2011) could have a 591 stronger link to condition when placed at this organ compared to the same pathway 
592 functioning on a peripheral tissue (i.e. epidermis). In such case, our mitoQ treatment,

593 even when administered at the same dosage in both species, could have imposed an 594 extra-cost to crossbills that, added to a probable poorer adaptation to captivity (see below), could have prevented to detect a significant effect on bird colour.

In contrast to mitoQ, mitoTEMPO raised the plasma levels of the two most abundant ketocarotenoids of our red crossbills, i.e. 3HOE and canthaxanthin (Table S2). MitoTEMPO-birds should, thus, have been able to increase the carotenoid transformation rate, probably at the mitochondria (Johnson and Hill, 2013). However, the transformation pathway of the two carotenoids differs. Whereas $3 \mathrm{HOE}$ values depend on $\beta$-cryptoxanthin availability, canthaxanthin would mostly result from $\beta$ carotene oxidation (Fig. S1). The absence of $\beta$-carotene in the blood of our carotenoidsupplemented birds may support the view that mitoTEMPO increased $\beta$-carotene conversion to canthaxanthin. The lack of circulating $\beta$-carotene has been reported in several avian species, including passerines fed with the pigment (reviewed in McGraw, 2006). Interestingly, in American flamingos (Phoenicopterus ruber), those birds fed with $\beta$-carotene did not show circulating $\beta$-carotene but increased blood canthaxanthin levels (Fox et al., 1969). We may, therefore, suggest that mitoTEMPO favoured $\beta$ carotene transformation at the intestine wall. This would imply the presence of the

610 CYP2J19 monooxygenase (Lopes et al., 2016; Mundy et al., 2016) or some specific $\beta$ 611 carotene ketolase probably at the enterocytes. However, such a possibility, as far as we 612 know, has never been reported for any species.

613 In any event, the most abundant red carotenoid in crossbill feathers is 3HOE (17 614 v.s $5 \mathrm{nmol} / \mathrm{g}$ for $3 \mathrm{HOE}$ and canthaxanthin, respectively; see ESM and del Val et al., 615 2009a). Its main substrate (i.e. $\beta$-cryptoxanthin) was well represented in blood and, 616 hence, carotenoid transformation at the liver can, in this case, be defended. Here, low617 redness (supposedly low-quality) birds treated with mitoTEMPO showed the highest 618 mean plasma values (Fig. 3), which supports our initial prediction (see introduction). 619 However, rump redness and total ketocarotenoid values in feathers, contrarily, indicate 620 that high-redness birds were the only individuals able to increase colour expression 621 when exposed to the cited mito-targeted antioxidant. In the case of total ketocarotenoid concentrations (Fig. 5A), we must consider the difficulties inherent to carotenoid extraction from feathers and, probably, the low sample size as potential reasons

624 explaining why the colour $\mathrm{x}$ treatment interaction was not significant (Table 2). 625 However, high-redness mitoTEMPO-birds showed significantly higher total 
626 ketocarotenoid concentrations than high-redness controls, which agrees with feather 627 redness (Fig. 5B).

628 Our results, intriguingly, suggest that mitoTEMPO did not only promoted carotenoid conversion in low-quality birds (Fig. 3) or in the whole of the sample (see

630 canthaxanthin above) but also ketocarotenoid allocation to feathers among high-quality

631 birds. That differential allocation can be deducted by the fact that, even when showing 632 higher feather redness and ketocarotenoid values than controls, high-redness birds 633 reported lower plasma $3 \mathrm{HOE}$ values than low-redness birds when treated with the antioxidant (Fig. 3). Thus, we could argue that the later was due to ketocarotenoids being sequestered by the feather follicles at a higher rate (i.e. a better allocation). In this regard, we performed alternative statistical tests to analyse if circulating $3 \mathrm{HOE}$ levels explained (canceled out) the results in feather models. We added plasma $3 \mathrm{HOE}$ values at the last sampling or, alternatively, the difference between final and initial $3 \mathrm{HOE}$ plasma values, as covariates in the models testing feather redness or ketocarotenoid concentration. These covariates were always significantly and positively correlated to redness and pigment levels in plumage (always $P<0.002$; slopes ranging from $0.33 \pm$ 0.04 to $0.89 \pm 0.11$ ). However, the interaction in the redness model (Table 2) and the comparison between high-redness mitoTEMPO-birds and high-redness controls in the feather ketocarotenoid model remained significant (all $P<0.02$ ). This suggests that the cited effects were independent of plasma $3 \mathrm{HOE}$ variability, at least at the time of blood sampling. In this regard, we must be cautious when interpreting circulatory values as blood sampling was restricted to a single point (day) after the treatment. Thus, we cannot fully discard that high-redness mitoTEMPO-birds could have previously produced and circulated the highest $3 \mathrm{HOE}$ levels favouring feather redness.

We must, anyway, highlight the limitations derived from captivity conditions that could have imposed an extra-cost for all the birds, perhaps making our initial prediction less realistic. In fact, no bird was able to regrowth the intense red rump exhibited by many wild crossbills (Fig. S2 in ESM). This agrees with initial studies in this species demonstrating that captivity severely limits the capacity of these animals to generate red feathers (Völker, 1957; Weber, 1961). In such overstressed conditions, only the best (reddest) individuals would still have been able to show a positive effect when the antioxidant state of the IMM was improved. 
660 Studies simultaneously testing mitochondrial and ketolase activities in model animal 661 species with ketocarotenoid-based ornamentation are now needed to disentangle the 662 mechanism involved in signalling and its ultimate evolutionary consequences. The 663 CYP2J19 discovery (Lopes et al., 2016; Mundy et al., 2016; also Twyman et al., 2018) 664 is exciting. However, although high levels of ketocarotenoids have been detected in the 665 IMM of a similar bird species (Ge et al., 2015; Hill et al., 2019), we need still 666 demonstrate that this or other monooxygenase enzymes in control of carotenoid 667 conversion are indeed placed into the mitochondrial membrane to support the main 668 IMMCOH assumption. Otherwise, if another cell site is involved (e.g. microsomes 669 where the CYP2J family has been described; Nebert et al., 2013), the idea should be 670 rethought to be well placed into the shared-pathway framework (Hill, 2011). Last but 671 not less, our study was not designed to assess if the amount (level) of substrate 672 carotenoids in the body could influence the efficiency of mito-targeted compounds in 673 promoting carotenoid transformations. This is another key point that merits future 674 experimental work if we aim to fully discard a role for resource-allocation trade-offs in 675 the evolution of red ketocarotenoid-based colourations as reliable signals of individual 676 quality.

677

\section{ETHICS}

679 This study was approved by the Bioethical Committees of CSIC (Ref. 404/2016) and 680 the local government (Junta de Comunidades de Castilla-La Mancha; Ref. 486728).

681

682 DATA ACCESSIBILITY

683 All data will be available at DIGITAL.CSIC repository.

684

\section{AUTHORS' CONTRIBUTIONS}

686 C.A.A. and A.C. carried out the experiment, analysed data and drafted the manuscript. 687 C.A.A. designed the study. D.A. and B.F.E. were responsible for crossbill captures and 688 data measurements in the field. P.C., R.M. and A.C. were involved in HPLC laboratory 689 analyses. All authors approve the publication and are accountable for this work.

690

691 FUNDING 
692 A.C. is supported by a postdoctoral fellowship from Fundación Ramón Areces.

693 Financial support was obtained from the project CGL2015-69338-C2-2-P (Ministerio de

694 Economía, Industria y Competitividad, MINECO, Spanish Government).

695

\section{COMPETING INTERESTS}

697 We have no competing interests.

698

\section{Acknowledgments}

700 We are grateful to Prof. Michael P. Murphy for kindly providing MitoQ and advice about its properties. We also thank Dr. Alberto Velando for earlier ideas on the use of mitoQ in testing evolutionary questions. We are grateful to Prof. Geoffrey Hill for advice on dietary carotenoid sources for our captive crossbills. We thank Pilar García Morchón and IFA staff for allowing to use their facilities as well as to Guillermo Mercé Arévalo for regularly obtaining pine-nuts and other aviary material. We finally thank Gustavo Liñán-Cembrano for support with SpotEgg software.

\section{REFERENCES}

Alonso-Alvarez, C. and Galván, I. (2011). Free radical exposure creates paler carotenoid-based ornaments: a possible interaction in the expression of black and red traits. Plos One 6, e19403.

Alonso-Alvarez, C., García-de Blas, E. and Mateo, R. (2018). Dietary canthaxanthin reduces xanthophyll uptake and red coloration in adult red-legged partridges. J Exp Biol. 221, jeb185074.

Alonso-Alvarez, C., Bertrand, S., Devevey, G., Gaillard, M., Prost, J.,

716 Faivre, B. and Sorci, G. (2004). An experimental test of the dose-dependent effect of 717 carotenoids and immune activation on sexual signals and antioxidant activity. Am Nat. 164, 651-659.

Allen, R. M. and Vickers, K. C. (2014). Coenzyme Q10 Increases Cholesterol Efflux and Inhibits Atherosclerosis Through MicroRNAs. 34, 1795-1797.

Biernaskie, J. M., Grafen, A. and Perry, J. C. (2014). The evolution of index signals to avoid the cost of dishonesty. Proc. R. Soc. B 281, 20140876.

Blount, J. D., Speed, M. P., Ruxton, G. D. and Stephens, P. A. (2009).

724 Warning displays may function as honest signals of toxicity. Proc. R. Soc. B 276, 871877. 
Britton, G., Liaaen-Jensen, S. and Pfander, H. (2004). Carotenoids. Handbook: Birkhäuser, Basel.

Cantarero, A. and Alonso-Alvarez, C. (2017). Mitochondria-targeted molecules determine the redness of the zebra finch bill. Biol Lett 13.

Carrín, M. E. and Carelli, A. A. (2010). Peanut oil: Compositional data. Eur. J. Lipid Sci. Technol. 112, 697-707.

Darwin, C. (1871). The Descent of Man, and Selection in Relation to Sex.

del Val, E., Borras, A., Cabrera, J. and Senar, J. C. (2009a). Plumage colour of male Common Crossbills Loxia curvirostra: visual assessment validated by colorimetry. Revista Catalana d'Ornitologia $\mathbf{2 5}$.

del Val, E., Negro, J. J., Garrido-Fernández, J., Jarén, M., Borràs, A., Cabrera, J. and Senar, J. C. (2014). Seasonal variation of red carotenoid pigments in plasma of wild Crossbill males Loxia curvirostra. J. Ornithol. 155, 211-218.

del Val, E., Senar, J. C., Garrido-Fernández, J., Jarén, M., Borràs, A., Cabrera, J. and Negro, J. J. (2009b). The liver but not the skin is the site for conversion of a red carotenoid in a passerine bird. Naturwissenschaften. 96, 797-801.

Dikalova, A. E., Bikineyeva, A. T., Budzyn, K., Nazarewicz, R. R., McCann, L., Lewis, W., Harrison, D. G. and Dikalov, S. I. (2010). Therapeutic Targeting of Mitochondrial Superoxide in Hypertension. Circ Res. 107, 106-116.

Endler, J. A. (1980). Natural selection on color patterns in Poecilia reticulata. Evolution 34, 76-91.

Fink, B. D., Guo, D. F., Kulkarni, C. A., Rahmouni, K., Kerns, R. J. and Sivitz, W. I. (2017). Metabolic effects of a mitochondrial-targeted coenzyme Q analog in high fat fed obese mice. Pharmacol Res Perspect. 5, e00301.

Fitze, P. S. and Richner, H. (2002). Differential effects of a parasite on ornamental structures based on melanins and carotenoids. Behav. Ecol. 13, 401-407.

Foley, J. D. and Van Dam, A. (1982). Fundamentals of interactive computer graphics: Addison-Wesley, Reading, MA.

Fox, D. L., Wolfson, A. A. and McBeth, J. W. (1969). Metabolism of $\beta$ carotene in the American flamingo, Phoenicopterus ruber. Comp Biochem Physiol. 29, 1223-1229.

Galván, I., Wakamatsu, K., Camarero, P. R., Mateo, R. and AlonsoAlvarez, C. (2015). Low-quality birds do not display high-quality signals: The cysteine-pheomelanin mechanism of honesty. Evolution 69, 26-38. 

Identification of carotenoid pigments and their fatty acid esters in an avian integument combining HPLC-DAD and LC-MS analyses. J Chromatogr B Analyt Technol Biomed Life Sci 879, 341-348.

García-de Blas, E., Mateo, R., Viñuela, J., Pérez-Rodríguez, L. and Alonso-

Alvarez, C. (2013). Free and esterified carotenoids in ornaments of an avian species: the relationship to color expression and sources of variability. Physiol. Biochem. Zool. 86, 483-498.

Ge, Z., Johnson, J. D., Cobine, P. A., McGraw, K. J., Garcia, R. and Hill, G. E. (2015). High concentrations of ketocarotenoids in hepatic mitochondria of Haemorhous mexicanus. Physiol Biochem Zool 88, 444-50.

Gómez, J. and Liñán-Cembrano, G. (2017). SpotEgg: an image-processing tool for automatised analysis of colouration and spottiness. J Avian Biol 48, 502-512. E. M. and Hall, A. M. (2018). The targeted anti-oxidant MitoQ causes mitochondrial swelling and depolarization in kidney tissue. Physiol Rep. 6, e13667. sexual coloration along an environmental gradient in guppies. Proc $R$ Soc Lond B 266, 1317-1317.

Gutiérrez-Tenorio, J., Marín-Royo, G., Martínez-Martínez, E., Martín, R., Miana, M., López-Andrés, N., Jurado-López, R., Gallardo, I., Luaces, M., San Román, J. A. et al. (2017). The role of oxidative stress in the crosstalk between leptin and mineralocorticoid receptor in the cardiac fibrosis associated with obesity. Sci Rep. 7, 16802 .

Hadfield, J. D. and Owens, I. P. F. (2006). Strong environmental determination of a carotenoid-based plumage trait is not mediated by carotenoid availability. $J$ Evol Biol. 19, 1104-1114.

Hasson, O. (1997). Towards a General Theory of Biological Signaling. J Theor Biol 185, 139-156.

Hill, G. E. (1994). Geographic-variation in male ornamentation and female mate preference in the house finch - a comparative test of models of sexual selection. Behav. 
Hill, G. E. (2011). Condition-dependent traits as signals of the functionality of vital cellular processes. Ecol Lett 14, 625-634.

Hill, G. E., Hood, W. R., Ge, Z., Grinter, R., Greening, C., Johnson, J. D., redness signals mitochondrial function in the house finch. Proc $R$ Soc Lond B 286, 20191354.

Hill, G. E., Inouye, C. Y. and Montgomerie, R. (2002). Dietary carotenoids predict plumage coloration in wild house finches. Proc. R. Soc. B 269, 1119-1124.

Hill, G. E. and Johnson, L. S. (2012). The vitamin A-redox hypothesis: a biochemical basis for honest signaling via carotenoid pigmentation. Am. Nat. 180, E127-50.

Hu, Q., Ren, J., Li, G., Wu, J., Wu, X., Wang, G., Gu, G., Ren, H., Hong, Z. and Li, J. (2018). The mitochondrially targeted antioxidant MitoQ protects the intestinal barrier by ameliorating mitochondrial DNA damage via the Nrf2/ARE signaling pathway. Cell Death Dis. 9, 403.

Hudon, J. (1994). Showiness, carotenoids, and captivity: a comment on Hill (1992). Auk 111, 218-221.

Inouye, C. Y., Hill, G. E., Stradi, R. D. and Montgomerie, R. (2001).

811 Carotenoids pigment in male house finch plumage in relation to age, subspecies, and ornamental coloration. Auk 118, 900-915, 16.

Jenni, L. and Winkler, R. (1994). Moult and ageing of European passerines. 814 London: Academic Press.

815 Jeong, E.-M., Chung, J., Liu, H., Go, Y., Gladstein, S., Farzaneh-Far, A., 816 Lewandowski, E. D. and Dudley, S. C. (2016). Role of Mitochondrial Oxidative Stress 817 in Glucose Tolerance, Insulin Resistance, and Cardiac Diastolic Dysfunction. J Am 818 Heart Assoc. 5, e003046.

819 Jlali, M., Graulet, B., Chauveau-Duriot, B., Godet, E., Praud, C., Nunes, C. 820 S., Le Bihan-Duval, E., Berri, C. and Duclos, M. J. (2014). Nutrigenetics of 821 carotenoid metabolism in the chicken: a polymorphism at the $\beta, \beta$-carotene 15,15 '-mono822 oxygenase 1 (BCMO1) locus affects the response to dietary $\beta$-carotene. $B r J$ Nutr. 111, 823 2079-2088.

824 Johnson, J. D. and Hill, G. E. (2013). Is carotenoid ornamentation linked to the 825 inner mitochondria membrane potential? A hypothesis for the maintenance of signal 826 honesty. Biochimie 95, 436-444. 
Koch, R. E. and Hill, G. E. (2018). Do carotenoid-based ornaments entail resource trade-offs? An evaluation of theory and data. Funct Ecol 32, 1908-1920.

830 Hill, G. E. (2019). Testing the resource trade-off hypothesis for carotenoid-based signal honesty using genetic variants of the domestic canary. J Exp Biol. 222, jeb188102.

Kodric-Brown, A. (1985). Female preference and sexual selection for male coloration in the guppy (Poecilia reticulata). Behav Ecol Sociobiol 17, 199-205.

Kodric-Brown, A. and Brown, J. H. (1984). Truth in Advertising: The Kinds of Traits Favored by Sexual Selection. Am Nat 124, 309-323.

Lessells, C. M. and Boag, P. T. (1987). Unrepeatable repeatabilities: a common mistake. Auk 104, 116-121. Mafalda S., Araujo, Pedro M., Melo-Ferreira, J., Andersson, L., Hill, Geoffrey E., Corbo, Joseph C. and Carneiro, M. (2016). Genetic basis for red coloration in birds. Curr. Biol. 26, 1427-1434.

Lozano, G. A. (1994). Carotenoids, parasites, and sexual selection. Oikos 70, 309-311.

Madonia, C., Hutton, P., Giraudeau, M. and Sepp, T. (2017). Carotenoid coloration is related to fat digestion efficiency in a wild bird. Naturwissenschaften 104, 96. Reactivity of ubiquinone and ubiquinol with superoxide and the hydroperoxyl radical: implications for in vivo antioxidant activity. Free Radic Biol Med. 46, 105-109. Press, Oxford, U.K.

McGraw, K. J. (2006). Mechanics of carotenoid-based coloration. Cambridge: Harvard University Press.

McGraw, K. J., Hill, G. E. and Parker, R. S. (2003). Carotenoid pigments in a mutant cardinal: implications for the genetic and enzymatic control mechanisms of carotenoid metabolism in birds. Condor 105, 587-592.

McGraw, K. J. and Toomey, M. B. (2010). Carotenoid accumulation in the 

(2007). Carotenoid-based colouration and ultraviolet reflectance of the sexual ornaments of grouse. Behav Ecol Sociobiol 61, 741-751. carotenoid coloration in the zebra finch is controlled by a cytochrome P450 gene cluster. Curr. Biol. 26, 1435-1440.

Murphy, M. P. and Smith, R. A. (2007). Targeting antioxidants to mitochondria by conjugation to lipophilic cations. Annu Rev Pharmacol Toxicol 47, $629-56$.

Nazarewicz, R. R., Dikalova, A., Bikineyeva, A., Ivanov, S., Kirilyuk, I. A., Grigor'ev, I. A. and Dikalov, S. I. (2013). Does scavenging of mitochondrial superoxide attenuate cancer prosurvival signaling pathways? Antioxid Redox Signal 19, 344-349.

Nebert, D. W., Wikvall, K. and Miller, W. L. (2013). Human cytochromes P450 in health and disease. Phil. Trans. R. Soc. B 368.

Panda, A. K. and Cherian, G. (2014). Role of vitamin E in counteracting oxidative stress in poultry. J Poultry Sci 51, 109-117.

Penn, D. J. and Számadó, S. (2019). The Handicap Principle: how an erroneous hypothesis became a scientific principle. Biol Rev, https://doi.org/10.1111/brv.12563. Darley-Usmar, V. M. (2013). Mitochondrially targeted compounds and their impact on cellular bioenergetics. Redox Biol. 1, 86-93.

Ridout, M. S., Demétrio, C. and Hinde, J. (1998). Models for count data with many zeros. In Proceedings of the XIXth International Biometric Conference, 179-192. Cape Town., vol. 19.

Rodríguez-Estival, J., Martínez-Haro, M., Martín-Hernando, M. P. and

888 Mateo, R. (2010). Sub-chronic effects of nitrate in drinking water on red-legged 889 partridge (Alectoris rufa): Oxidative stress and T-cell mediated immune function. 890 Environ Res. 110, 469-475. 

Delivery of bioactive molecules to mitochondria in vivo. Proc Natl Acad Sci USA 100, 5407-5412.

897

Svensson, P. A. and Wong, B. (2011). Carotenoid-based signals in behavioural

898

899

900

901

902

903

904

905

906

907

908

909

910

911

912

913

914

915

916

917

918

919

920

921

922

923

924

925

926

927 ecology: A review. Behaviour 148, 131-189.

Toomey, M. B., Lopes, R. J., Araújo, P. M., Johnson, J. D., Gazda, M. A., Afonso, S., Mota, P. G., Koch, R. E., Hill, G. E., Corbo, J. C. et al. (2017). Highdensity lipoprotein receptor SCARB1 is required for carotenoid coloration in birds. Proc Natl Acad Sci USA 114, 5219-5224.

Trnka, J., Blaikie, F. H., Smith, R. A. J. and Murphy, M. P. (2008). A mitochondria-targeted nitroxide is reduced to its hydroxylamine by ubiquinol in mitochondria. Free Radic Biol Med. 44, 1406-1419.

Trnka, J., Elkalaf, M. and Anděl, M. (2015). Lipophilic triphenylphosphonium cations inhibit mitochondrial electron transport chain and induce mitochondrial proton leak. Plos One 10, e0121837.

Twyman, H., Prager, M., Mundy, N. I. and Andersson, S. (2018). Expression of a carotenoid-modifying gene and evolution of red coloration in weaverbirds (Ploceidae). Mol Ecol. 27, 449-458.

Vendrov, A. E., Vendrov, K. C., Smith, A., Yuan, J., Sumida, A., Robidoux, J., Runge, M. S. and Madamanchi, N. R. (2015). NOX4 NADPH oxidase-dependent mitochondrial oxidative stress in aging-associated cardiovascular disease. Antioxid Redox Signal. 23, 1389-1409.

Völker, O. (1957). Die experimentelle Rotfarbung des Gefieders beim Fichtenkreuzschnabel (Loxia curvirostra). J. Ornithol. 98, 210-214.

von Schantz, T., Bensch, S., Grahn, M., Hasselquist, D. and Wittzell, H. (1999). Good genes, oxidative stress and condition-dependent sexual signals. Proc $R$ Soc B. 266, 1-12.

Wallace, A. R. (1877). The Colors of Animals and Plants. Am Nat. 11, 641-662.

Wang, A., Keita, A. V., Phan, V., McKay, C. M., Schoultz, I., Lee, J., Murphy, M. P., Fernando, M., Ronaghan, N., Balce, D. et al. (2014). Targeting mitochondria-derived reactive oxygen species to reduce epithelial barrier dysfunction and colitis. Am J Pathol. 184, 2516-2527.

Weber, H. (1961). Über die Ursache des Verlustes der roten Federfarbe bei gekäfigten Birkenzeisigen. J. Ornithol. 102, 158-163. 
929 Nishimura, E., Yamamori, T., Yamasaki, T., Yamada, K.-i. et al. (2017). Lipophilic

930 triphenylphosphonium derivatives enhance radiation-induced cell killing via inhibition

931 of mitochondrial energy metabolism in tumor cells. Cancer Lett. 390, 160-167.

932 Zielonka, J., Joseph, J., Sikora, A., Hardy, M., Ouari, O., Vasquez-Vivar, J.,

933 Cheng, G., Lopez, M. and Kalyanaraman, B. (2017). Mitochondria-Targeted

934 Triphenylphosphonium-Based Compounds: Syntheses, Mechanisms of Action, and

935 Therapeutic and Diagnostic Applications. Chem Rev. 117, 10043-10120.

936

937 
938 Table 1. Generalized linear models testing the impact of mito-targeted antioxidant 939 treatments and their interaction with colour category on the level of circulating 940 pigments and vitamins of captive male crossbills.

\begin{tabular}{lccrrrr}
\hline $\begin{array}{l}\text { Dependent variable (Distribution) } \\
\text { Terms in the model }\end{array}$ & Estimate & SE & d.f.s & $\chi^{2}$ & $\boldsymbol{P}$ \\
\hline $\boldsymbol{\beta}$-cryptoxanthin (Normal) & & & & & \\
\hline $\begin{array}{l}\text { Initial value covariate } \\
\text { Antioxidant treatment }\end{array}$ & 0.571 & 0.206 & 1 & 7.66 & 0.006 \\
& & & 2 & 32.47 & $<0.001$ \\
Lutein (Normal) & & & & & \\
\hline Initial value covariate & 0.527 & 0.088 & 1 & 35.73 & $<0.001$ \\
Antioxidant treatment & & & 2 & 9.95 & 0.007 \\
& & & & & \\
Unidentified Xanthophylls (Normal) & & & & & \\
\hline $\begin{array}{l}\text { Initial value covariate } \\
\text { Antioxidant treatment }\end{array}$ & 0.570 & 0.0935 & 1 & 37.10 & $<0.001$ \\
& & & 2 & 7.77 & 0.021
\end{tabular}

Total tocopherol (Normal)

\begin{tabular}{llllll}
\hline Initial value covariate & 0.718 & 0.141 & 1 & 25.96 & $<0.001$ \\
Antioxidant treatment & & & 2 & 18.88 & $<0.001$
\end{tabular}

Canthaxanthin (Negative Binomial)

\begin{tabular}{llllll}
\hline Initial value covariate & 0.0002 & 0.0001 & 1 & 4.83 & 0.0279 \\
Antioxidant treatment & & & 2 & 6.63 & 0.0363
\end{tabular}

$\begin{array}{llllll}\text { Zero inflation model } & & & & & \\ \text { Initial value covariate } & -0.002 & 0.001 & 1 & 9.59 & 0.002\end{array}$

3-HOE (Negative Binomial)

\begin{tabular}{|c|c|c|c|c|c|}
\hline Initial value covariate & 0.002 & 0.001 & 1 & 7.73 & 0.005 \\
\hline Colour category & & & 1 & 1.69 & 0.194 \\
\hline Antioxidant treatment & & & 2 & 12.69 & 0.002 \\
\hline Interaction & & & 2 & 9.75 & 0.008 \\
\hline
\end{tabular}

$\underline{\text { Zero inflation model }}$

Initial value covariate

Antioxidant treatment

$\begin{array}{lllll}-0.012 & 0.006 & 1 & 4.46 & 0.035 \\ & & 2 & 4.86 & 0.088 \\ 3.374 & 1.548 & 1 & 4.75 & 0.029 \\ 0.480 & 1.053 & 1 & 0.21 & 0.648\end{array}$

941 Note: Type of distribution, the slopes for covariates as well as Likelihood Ratio $\chi^{2}$ tests and P-values

942 are reported. Negative binomial models show the main outputs for counting and zero-inflated parts of

943 the models. 
945 Table 2. Generalized linear models testing the impact of mito-targeted antioxidant

946 treatments and colour category on the values of feather carotenoids and rump

947 coloration of captive male Eurasian crossbills.

\begin{tabular}{llllll}
\hline Dependent variable (Distribution) & Estimate & SE & d.f.s & $\chi^{2}$ & $P$
\end{tabular}

Terms in the model

B-cryptoxanthin (Negative Binomial)

$\begin{array}{llll}\text { Antioxidant treatment } & 2 & 14.92 & 0.001\end{array}$

UD- $\beta$-cryptoxanthin (Negative Binomial)

\begin{tabular}{llll}
\hline Antioxidant treatment & 2 & 10.51 & 0.005
\end{tabular}

Echinenone (Negative Binomial)

Antioxidant treatment

$2 \quad 12.03 \quad 0.002$

Log-Total red ketocarotenoids (Normal)

$\begin{array}{llll}\text { Colour category } & 1 & 0.01 & 0.957 \\ \text { Antioxidant treatment } & 2 & 2.21 & 0.331 \\ \text { Interaction } & 2 & 3.58 & 0.167\end{array}$

Rump redness (Normal)

\begin{tabular}{lrrrrr}
\hline Saturation & 6.409 & 4.790 & 1 & 1.79 & 0.181 \\
Brightness & -6.145 & 6.408 & 1 & 3.54 & 0.059 \\
Colour category & & & 2 & 1.5 & 0.221 \\
Antioxidant treatment & & & 2 & 3.89 & 0.143 \\
Interaction & & & 1 & 7.93 & 0.019
\end{tabular}

Note: Type of distribution, the slopes for covariates as well as Likelihood Ratio $\chi^{2}$ tests and $P$ -

949 values are reported. Negative binomial models show the main outputs for counting and zero-

$950 \quad$ inflated parts of the models.

951

952 
bioRxiv preprint doi: https://doi.org/10.1101/839670; this version posted November 13, 2019. The copyright holder for this preprint (which was not certified by peer review) is the author/funder. All rights reserved. No reuse allowed without permission.

953 Fig. 1. Molecular structure of the two mito-targeted antioxidants and their 954 situation into the inner mitochondrial membrane and electron transport chain.

955

956

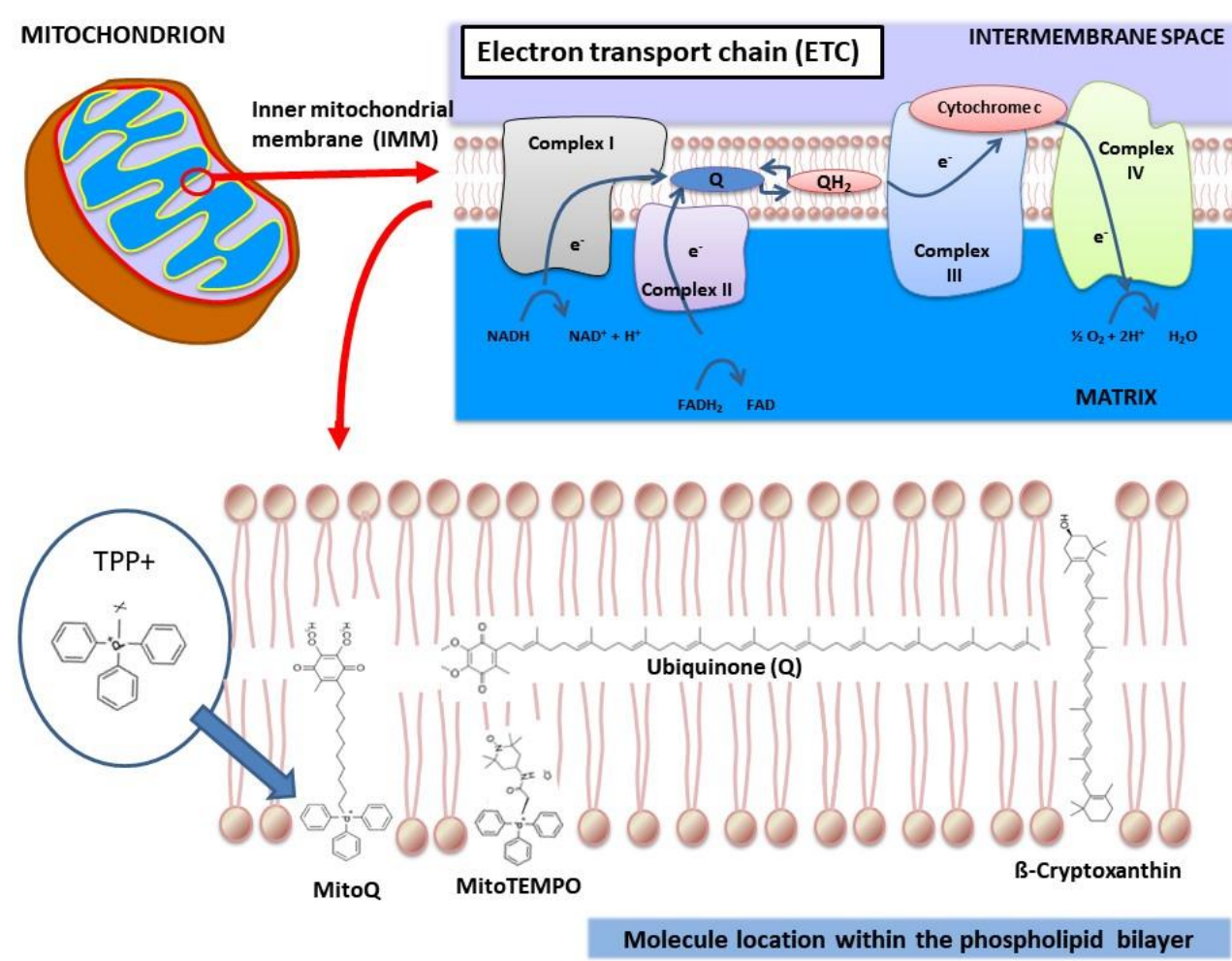


959 Fig. 2. Variability in circulating levels of carotenoids and tocopherol in Eurasian 960 crossbills after treatment with mito-targeted antioxidants. Least square means \pm 961 SEs from models. LSD pairwise tests: **: $P<\mathbf{0 . 0 1}, *: P>0.05$.

962

963
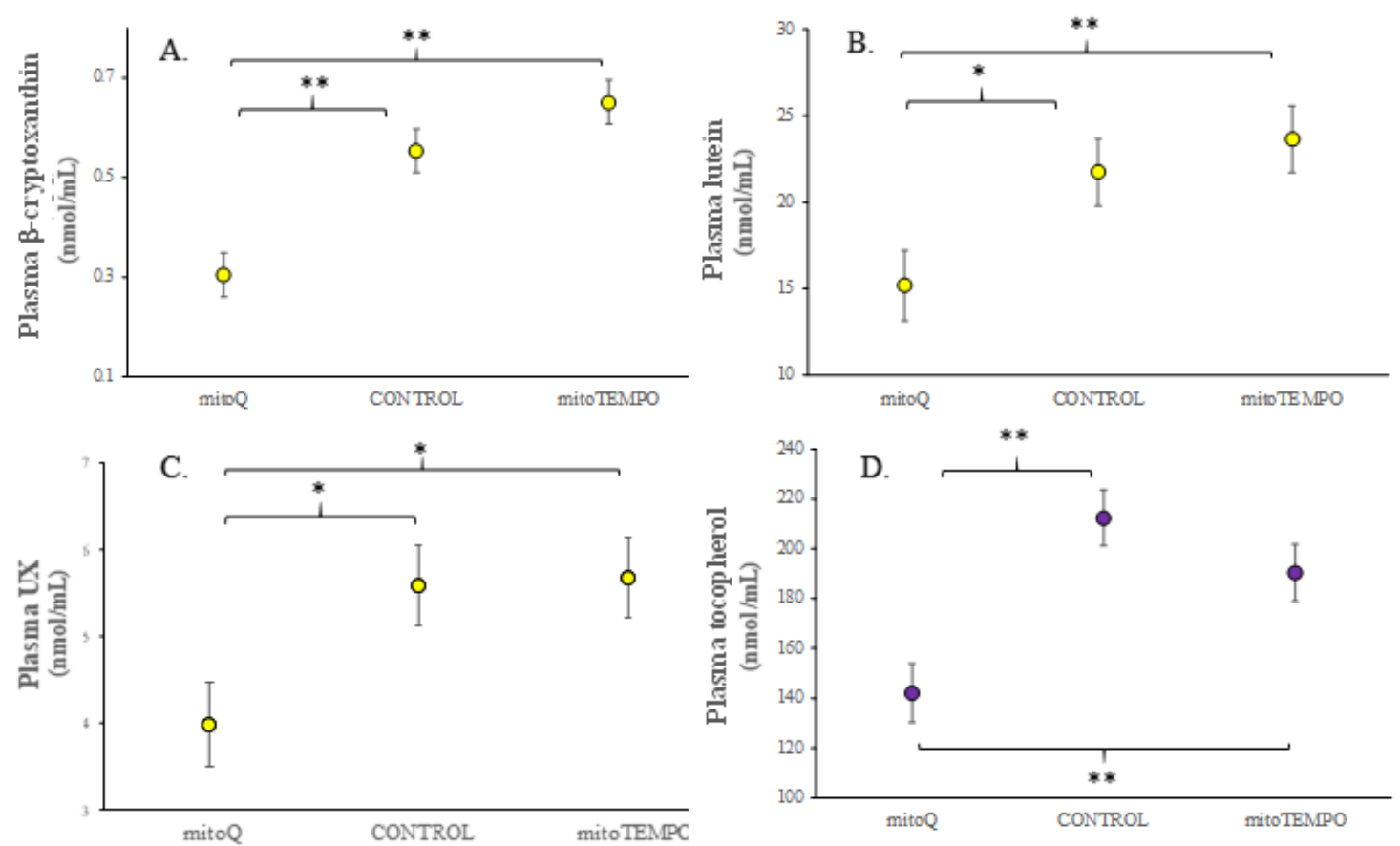

965

966

967

968

969

970 
971 Fig. 3. Variability in circulating levels of the red ketocarotenoid 3HOE in red 972 crossbills after treatment with mito-targeted antioxidants. High- or low-redness 973 groups identify those birds over or below the median value of rump redness at the 974 start of the experiment. Least square means \pm SEs from models. LSD pairwise 975 tests: **: $P<\mathbf{0 . 0 1}, *: P>\mathbf{0 . 0 5} ; \uparrow: P<\mathbf{0 . 1 0}$.

976

977

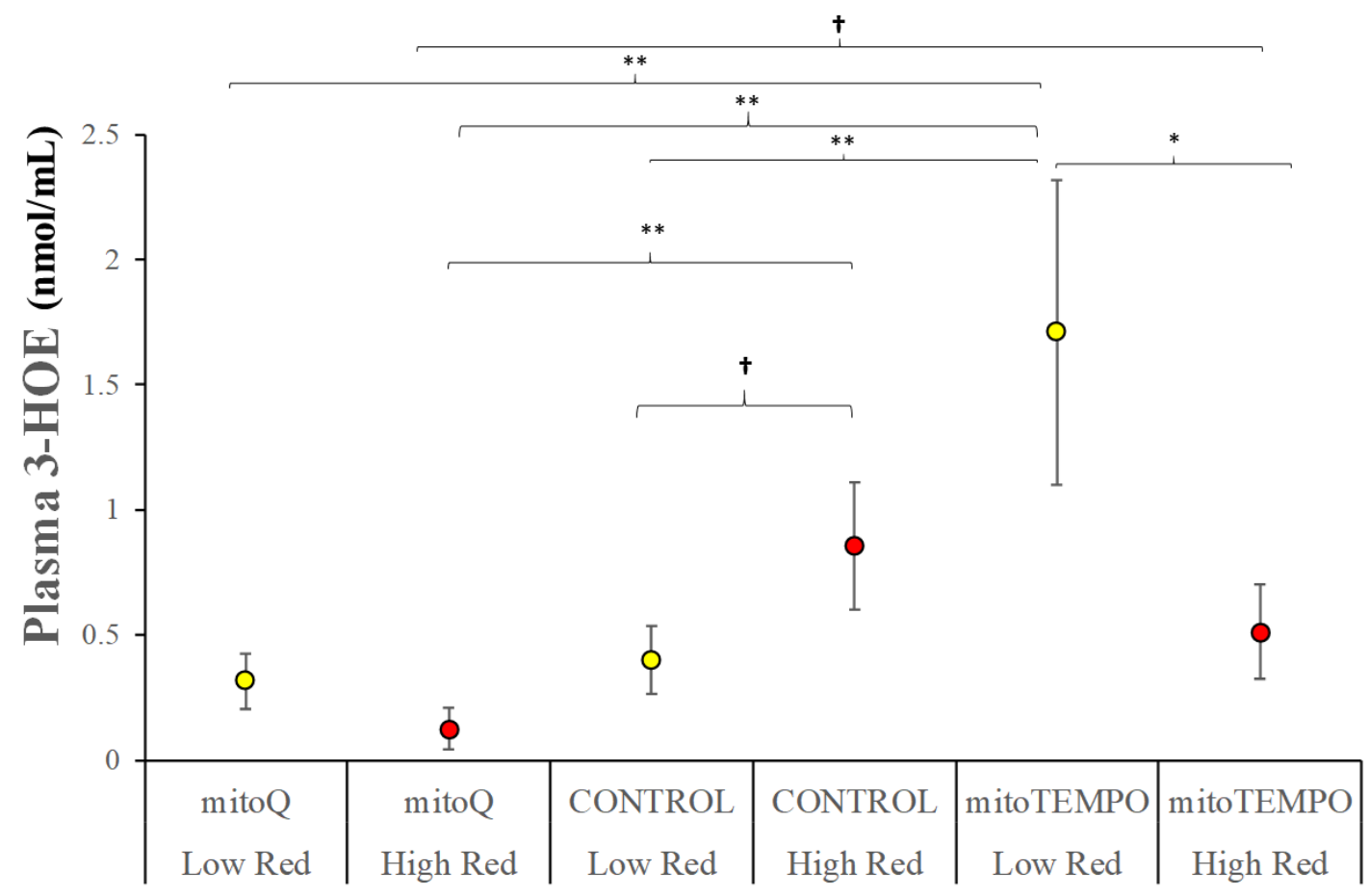

978 
979 Fig. 4. Variability in feather concentration of carotenoids in Eurasian crossbills 980 after treatment with mito-targeted antioxidants. Least square means \pm SEs from 981 models. LSD pairwise tests: **: $P<\mathbf{0 . 0 1}, *$ : $P>0.05$.

982
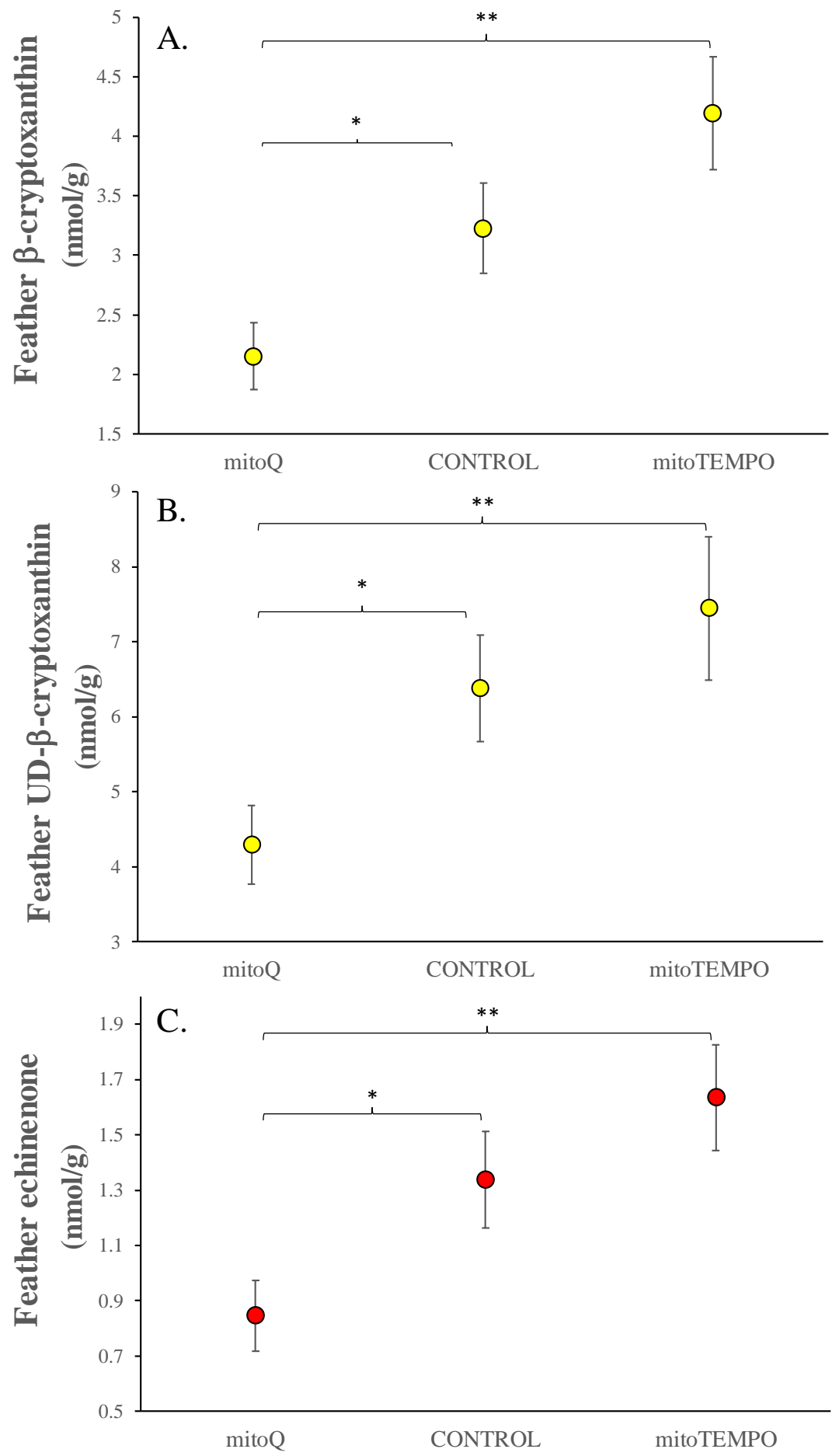
987 Fig. 5. Variability in the total level of red ketocarotenoids in rump feathers (A) as 988 well as rump redness variability (B) in Eurasian crossbills after treatment with two 989 different mito-targeted antioxidants. High- or low-redness groups identify those 990 birds over or below the median value of rump redness at the start of the 991 experiment. Least square means \pm SEs from models. LSD pairwise tests: **: $P$ < $9920.01, *: P>0.05 ; \uparrow: P<\mathbf{0 . 1 0}$.

993

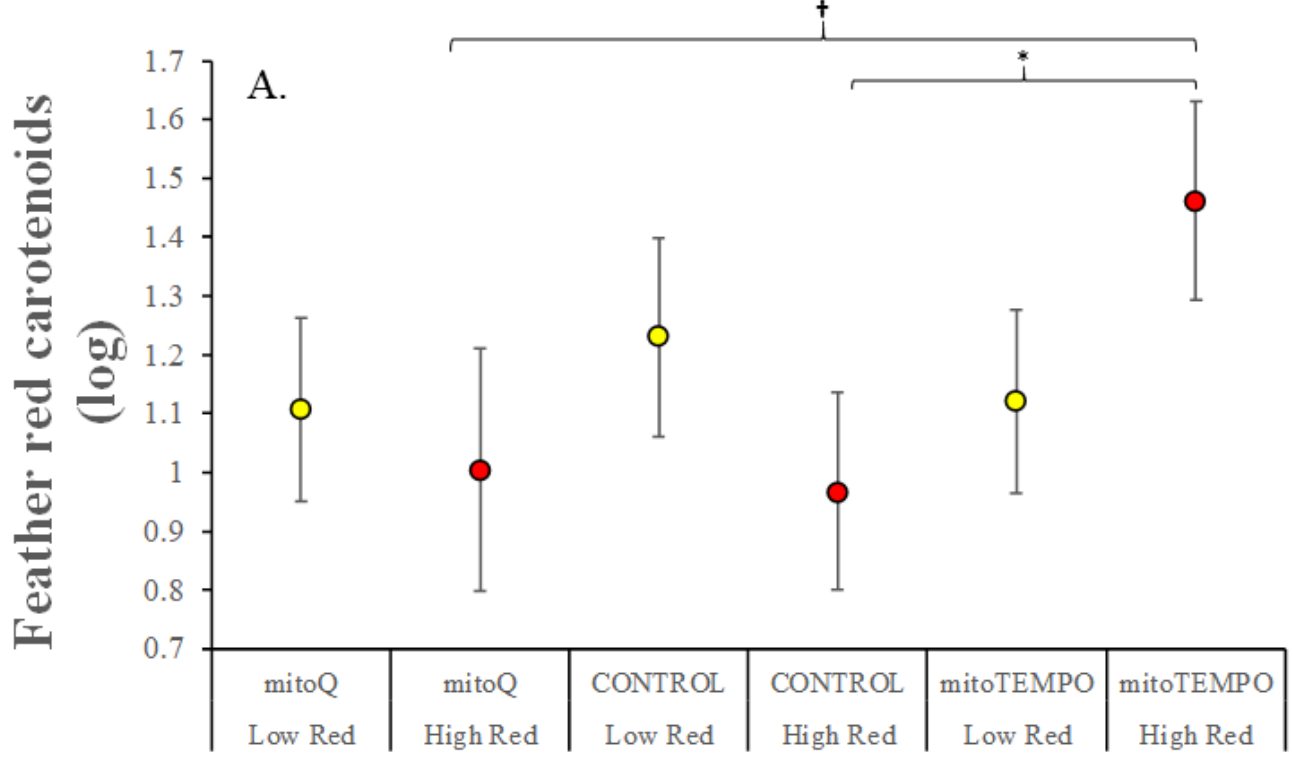

994

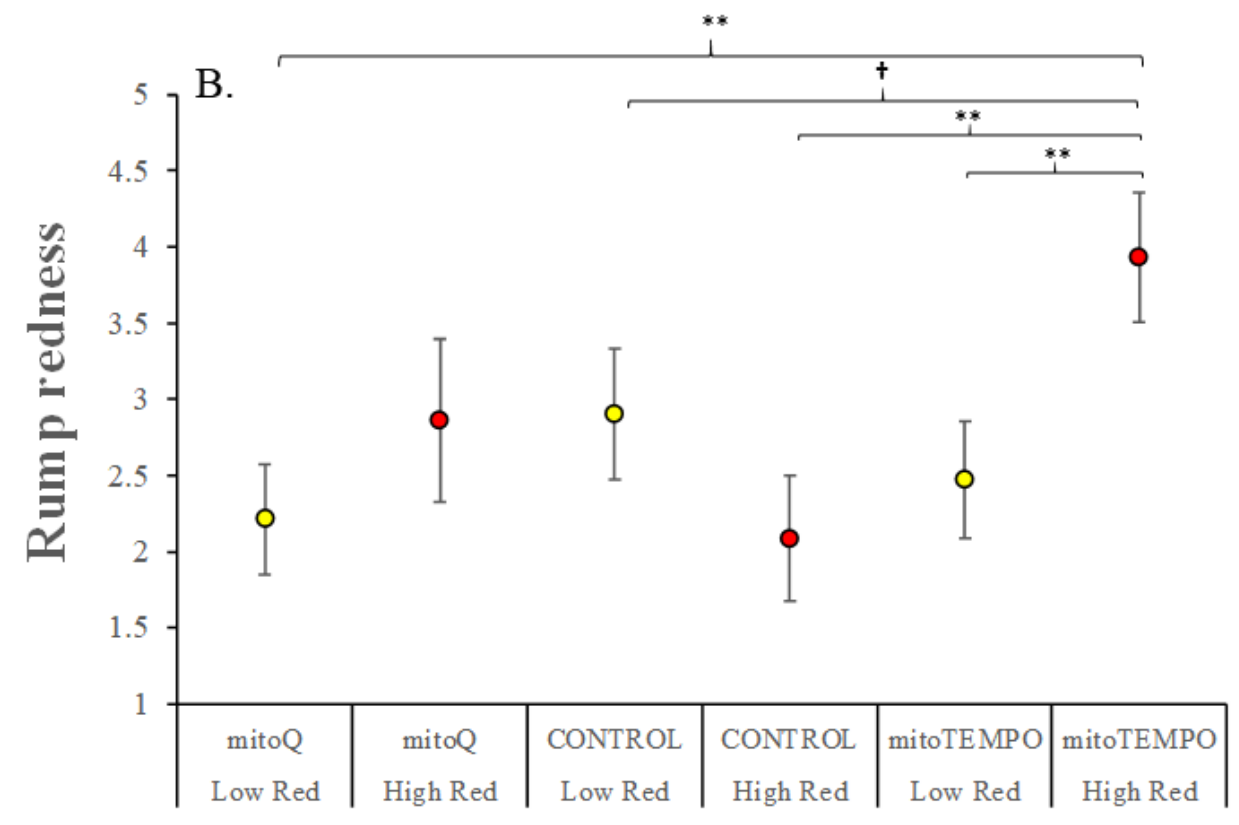

